\title{
Microwave-Assisted Syntheses of Thiophene-Based Ionic Liquids: Structural Design and Optimization
}

\author{
María A. Schiel \\ Claudia E. Domini* \\ Alicia B. Chopa \\ Gustavo F. Silbestri* (D) \\ Instituto de Química del Sur (INQUISUR), Departamento \\ de Química, Universidad Nacional del Sur (UNS)-CONICET, \\ Av. Alem 1253, B8000CPB Bahía Blanca, Argentina \\ cdomini@criba.edu.ar \\ gsilbestri@uns.edu.ar
}

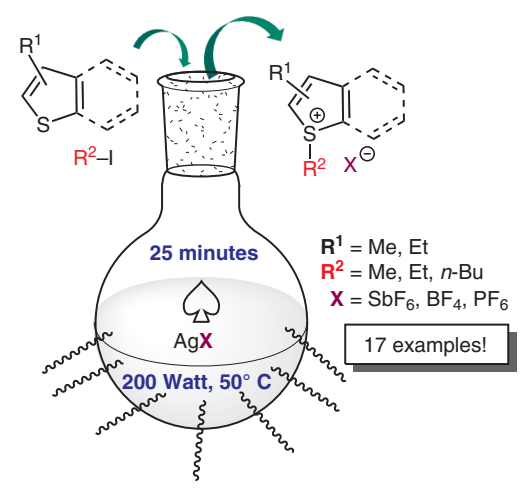

Received: 29.06.2018

Accepted after revision: 29.07.2018

Published online: 21.08 .2018

DOI: 10.1055/s-0037-1609934; Art ID: ss-2018-m0445-op

Abstract This manuscript explores microwave-assisted reactions for the synthesis of new ionic materials involving the S-alkylation of thiophene. All isolatable products have been fully characterized by NMR and all product have been quantified through UV-vis spectroscopy. By means of a design technique, the experimental protocol (25 min, 200W, $50^{\circ} \mathrm{C}$ ) has been optimized, which led us to better yields (96\%). In the absence of MW activation, the conventional thermal reaction at room temperature took longer (24-48h) to obtain similar results.

Keywords thiophenium salt, ionic liquid, syntheses, microwave, experimental design

The principle of 'sustainable development'1 has promoted major changes in the advancement of chemistry; the search for alternatives to conventional organic solvents and the development of methodologies to optimize the use of resources are some of them. ${ }^{2}$ A series of novel ionic liquids (ILs) that expand the range of traditional structures have been reported by some research groups, ${ }^{3-5}$ thus enlarging their chemical applications. ${ }^{6-9}$ By definition, ILs are organic compounds formed by ions with melting points below $100^{\circ} \mathrm{C}$. Generally, they are composed of a bulky cation that comes from the quaternization of a nitrogen heterocycle, different alkylamines, or phosphines and various organic or inorganic anions. Depending on the size and characteristics of each one, ILs may be more or less hydrophobic. Most ILs are monovalent and their liquid state is derived from the divergent size between cations and anions, which make them unable to generate a stable crystal lattice, as well as the poor coordinating ability and low intermolecular interactions of anions. They are often characterized by their thermal stability, ${ }^{10}$ high ionic conductivity, low vapor pressure, and tunable miscibility with both water and organic solvents. ${ }^{11}$ Nevertheless, Burrell and co-workers ${ }^{12}$ have shown that the thermal stability of some ILs is much lower than expected with respect to other derivatives studied before. Besides, Endres and El Abedin reported that a decrease in the melting point is due to an increase in anion size. ${ }^{13}$ These systems are widely used either as extractants in analytical chemistry $^{8}$ or in organic synthesis as a new set of environmentally friendly solvents. ${ }^{7}$ It is important to mention that, as far as we know, there are few reports about salts derived from thiophene. ${ }^{14-16}$ The first reactions of thiophene and bromobutane assisted by ultrasound were carried out in our group; the synthesized $S$-butylthiophenium bromide proved to be relatively stable in aqueous solution and could be stored for weeks without decomposing. ${ }^{17}$

On the other hand, microwave-assisted chemistry is no longer an unconventional method and it has become a routine technique in organic synthesis laboratories. ${ }^{18,19} \mathrm{MW}$ heating reduces the reaction times and, in some cases, can generate transformations that would not be possible under other conditions. ${ }^{20-22}$ The most important benefit of applying microwave irradiation is that the mixtures can be heated rapidly to the desired temperature. Among substances with significant ionic bonding, the synthesis of, and with ionic liquids (ILs) represent paradigmatic examples. ${ }^{23-25}$ MW irradiation has also been successfully applied to solvothermal synthesis of inorganic compounds, both molecular and non-molecular (i.e., having iono-covalent bonding). ${ }^{26,27}$ Moreover, MW frequency effects have been reported in the synthesis of ionic liquids. ${ }^{28}$

In all chemical processes a considerable number of variables (instrumental parameters, reagents, times, temperatures, etc.) are present so a large number of experiments must be carried out in order to define the optimal conditions. Using a univariate strategy (one-factor-at-a-time optimization) is an intricate approach to evaluate the effects of different variables on an experimental outcome. In addition, this method is time consuming, expensive, and often 
leads to misinterpretation of results when interactions between different components are present. The experimental design (ED) could be defined as a mathematical method helping experimentalists to: (i) select the optimal experimental synthetic strategy through a fewer number of experiments, and (ii) evaluate the experimental results in order to assure maximum reliability on the obtained conclusions. Nowadays, the multivariate technique is used to improve the optimization process in chemistry. ${ }^{29}$ To meet this goal, response surface methodology can be used as a remarkable strategy to apply in this process. ${ }^{30}$

Here, and in line with previous research, we explore the synthesis assisted by MW of new ionic liquids by S-alkylation of thiophenes (Scheme 1). The products have been characterized by spectroscopic methods, and as mentioned the experimental design (ED) technique ${ }^{31}$ allows the optimization of conditions leading to better yields in shorter times.

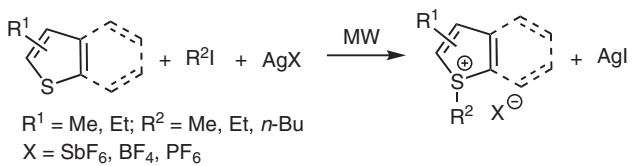

Scheme 1 Synthesis of S-alkylthiophenium salts

Initially we studied the microwave-assisted synthesis without any additives. In this way, various combinations of thiophenes [thiophene, 2-ethylthiophene, 3-methylthiophene, 2,5-dimethylthiophene, thianaphthene (ben$\mathrm{zo}[b]$ thiophene)], alkylating agents ( $\mathrm{BuBr}$, BuI, $\mathrm{MeI}, \mathrm{Me}_{2} \mathrm{SO}_{4}$, $\mathrm{BnCl}, t-\mathrm{BuCl}$, allyl bromide) and solvents $\left(\mathrm{H}_{2} \mathrm{O}, \mathrm{EtOH}, \mathrm{MeCN}\right.$, DCE, hexane, heptane, DMSO, o-dichlorobenzene) were irradiated under different reaction conditions (time, microwave power, temperature). Unfortunately, in all the reactions only starting materials were recovered along with some polymeric degradation byproducts. Taking into account these negative results we decided to carry out the reactions in the presence of different silver salts. ${ }^{14}$

First, in order to isolate and characterize some of the products, a modification of the method used by Achenson and Harrison was employed. ${ }^{14}$ In this way, 1-methylbenzo[b]thiophenium hexafluoroantimonate was isolated in $63 \%$ yield by stirring overnight at room temperature benzo[b]thiophene, methyl iodide, and silver hexafluoroantimonate in 1,2-dichloroethane (DCE). The corresponding reaction workup has been described elsewhere. ${ }^{13}$ A similar quaternization method was employed for thiophene, 2,5dimethylthiophene, 2-ethylthiophene and 3-methylthiophene, although the workup had to be modified (see Experimental Section). For each thiophene, the reaction was carried out with different silver salts, such as silver hexafluoroantimonate $\left(\mathrm{AgSbF}_{6}\right)$, silver 4-toluenesulfonate (AgOTs), silver thiocyanate (AgSCN), and silver bis(trifluoromethylsulfonyl)imide $\left(\mathrm{AgNTf}_{2}\right)$. Unfortunately, the only thiopheni- um salt that could be isolated (10\% yield) and unequivocally characterized was 1,2,5-trimethylthiophenium hexafluoroantimonate. This salt was chosen to carry out the experimental design. The rest of the salts could not be isolated due to their rapid decomposition. It is worth mentioning the appearance of coloration in the supernatant ranging from light yellow to dark purple, passing through red and green. In general terms, coloration, from the lightest to the darkest for all quaternizations depends on the salts used: AgSCN $<\mathrm{AgOTs}<\mathrm{AgNTf}_{2}<\mathrm{AgSbF}_{6}$. On the basis of previous literature data ${ }^{32-34}$ and a few transmission electron microphotographs (TEM) (Supporting Information, S14), the presence of colloidal silver was confirmed, probably promoted by oxidation of solvent or thiophenes.

The result of an ED is a polynomial regression describing how different variables (through their coefficients) affect the result of a system either independently or interacting one with another. The most common empirical models fit to experimental data are either linear or quadratic equations. ${ }^{35}$ The following is a general second order equation describing a three variable system $\left(\mathrm{x}_{1}, \mathrm{x}_{2}, \mathrm{x}_{3}\right)$, with a response y:

$\mathrm{y}=\beta_{0}+\beta_{1} \mathrm{x}_{1}+\beta_{2} \mathrm{x}_{2}+\beta_{3} \mathrm{x}_{3}+\beta_{11} \mathrm{x}_{1}^{2+}+\beta_{22} \mathrm{x}_{2}^{2+}+\beta_{33} \mathrm{x}_{3}^{2+}+\beta_{12} \mathrm{x}_{1} \mathrm{x}_{2}+\beta_{13} \mathrm{x}_{1} \mathrm{x}_{3}+\beta_{23} \mathrm{x}_{2} \mathrm{x}_{3}$

Where $\beta_{0}$ is the origin coordinate; $\beta_{1}, \beta_{2}, \beta_{3}$ are first order coefficients; $\beta_{11}, \beta_{22}, \beta_{33}$ are quadratic ones and $\beta_{12}, \beta_{13}$, $\beta_{23}$ are interaction coefficients.

Different designs can provide this type of model fitting. One of the most employed is the central composite design (CCD), which allows the prediction of the first and second order coefficients, making possible the estimation of a surface response and interactions between variables. ${ }^{31,36,37}$

Three variables were optimized in our synthesis: irradiation time (factor A), irradiation power (factor B), and temperature (factor $C$ ). Each parameter was studied at two levels, high (+1) and low (-1) arranged in a full factorial matrix. As can be seen in Figure 1, all combinations of experimental conditions can be represented in a three-dimension Cartesian coordinate system. The design is formed by a cube whose corner points (circles) represent a full-factorial design. In addition, this design has a central point (triangles) and six star points outside the cube (squares) with coded values at a distance of $\pm 1.68( \pm \alpha)$ the center for one of the variables, while the others are kept at 0 of the central point (level 0).

Table 1 shows the levels evaluated for each factor with its coded and real experimental conditions. All reactions were carried out with equimolar amounts of 2,5-dimethylthiophene and silver hexafluoroantimonate and 1.5 times excess of methyl iodide in DCE as solvent. The experiments listed in Table 1 match the numbers given in the cube in Figure 1.

From this equation (see table 1, footnote b), the optimal conditions for maximum yield could be established as fol- 


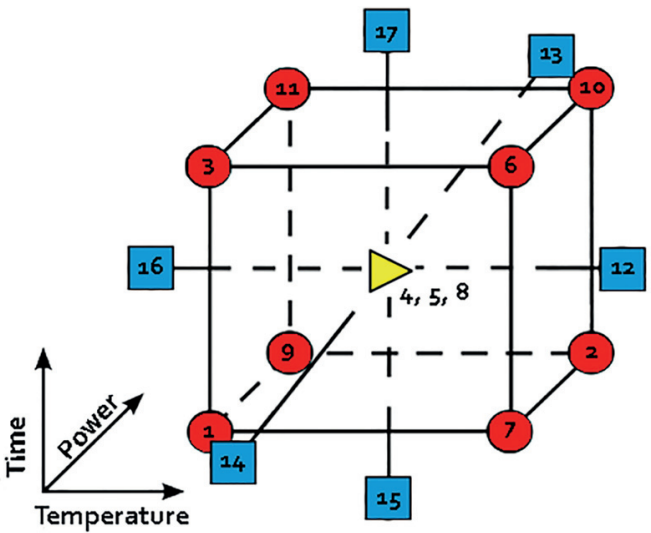

Figure 1 Experimental domain for a three variable optimization CCD

lows: $25 \mathrm{~min}$ at $200 \mathrm{~W}$ of power and $50^{\circ} \mathrm{C}$. These conditions concur with experiment 3 in Table1. Reactions carried out by triplicate gave $96 \%$ yield. Below, a Pareto chart (Figure 2 ) of normalized effects of these factors is drawn. The Factor A (time) is the only significant variable.

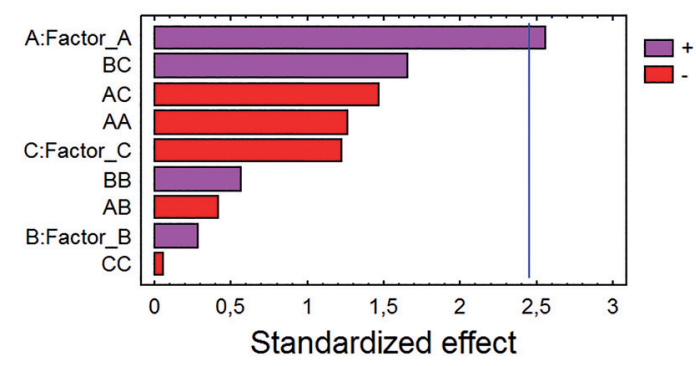

Figure 2 Standardized Pareto chart for optimized variables. Factor A: irradiation time; Factor B: irradiation power; Factor C: temperature. The vertical line (blue) crossing the Pareto chart indicates the significant variables with respect to the response.

The optimal conditions found were employed for the preparation of different thiophenium salts by varying substitution positions in the starting thiophene ring (2,5-dimethylthiophene, 2-ethylthiophene, 3-methylthiophene, benzo[ $b]$ thiophene, 2-methylbenzo[ $b]$ thiophene), anions $\left(\mathrm{SbF}_{6}{ }^{-}, \mathrm{BF}_{4}^{-}, \mathrm{PF}_{6}{ }^{-}\right)$, and alkylating agents (MeI, EtI, BuI, BnCl, allyl bromide, $t$-BuCl). It is important to mention that when methyl iodide was used as the alkylating agent, all the ex-

Table 1 Levels of Experimental Variables and Their Corresponding Response Values of the Designa,b

\begin{tabular}{|c|c|c|c|c|c|c|c|}
\hline \multirow[t]{3}{*}{ Experiment } & \multicolumn{6}{|c|}{ Independent variables } & \multirow[t]{3}{*}{ Yield (\%) } \\
\hline & \multicolumn{2}{|c|}{$\begin{array}{l}\text { Factor A } \\
\text { Time (min) }\end{array}$} & \multicolumn{2}{|c|}{$\begin{array}{c}\text { Factor B } \\
\text { Power (Watt) }\end{array}$} & \multicolumn{2}{|c|}{$\begin{array}{c}\text { Factor } \mathrm{C} \\
\text { Temp }\left({ }^{\circ} \mathrm{C}\right)\end{array}$} & \\
\hline & Coded level & Actual level & Coded level & Actual level & Coded level & Actual level & \\
\hline 1 & -1 & 15 & -1 & 200 & -1 & 50 & 79.9 \\
\hline 2 & -1 & 15 & 1 & 270 & 1 & 70 & 90.0 \\
\hline 3 & 1 & 25 & -1 & 200 & -1 & 50 & 97.6 \\
\hline 4 & 0 & 20 & 0 & 235 & 0 & 60 & 76.6 \\
\hline 5 & 0 & 20 & 0 & 235 & 0 & 60 & 81.2 \\
\hline 6 & 1 & 25 & -1 & 200 & 1 & 70 & 66.7 \\
\hline 7 & -1 & 15 & -1 & 200 & 1 & 70 & 63.9 \\
\hline 8 & 0 & 20 & 0 & 235 & 0 & 60 & 66.0 \\
\hline 9 & -1 & 15 & 1 & 270 & -1 & 50 & 57.0 \\
\hline 10 & 1 & 25 & 1 & 270 & 1 & 70 & 69.7 \\
\hline 11 & 1 & 25 & 1 & 270 & -1 & 50 & 81.2 \\
\hline 12 & 0 & 20 & 0 & 235 & 1.69 & 77 & 68.1 \\
\hline 13 & 0 & 20 & 1.69 & 293 & 0 & 60 & 95.4 \\
\hline 14 & 0 & 20 & -1.69 & 170 & 0 & 60 & 80.5 \\
\hline 15 & -1.69 & 12 & 0 & 235 & 0 & 60 & 30.1 \\
\hline 16 & 0 & 20 & 0 & 235 & -1.69 & 43 & 91.6 \\
\hline 17 & 1.69 & 28 & 0 & 235 & 0 & 60 & 97.1 \\
\hline
\end{tabular}

a Reaction conditions: 2,5 -dimethylthiophene $(0.1 \mathrm{mmol})$, Mel $(0.15 \mathrm{mmol}), \mathrm{AgSF}_{6}(0.1 \mathrm{mmol}), \mathrm{DCE}(1 \mathrm{~mL})$.

${ }^{b}$ Data obtained fitted to a second order regression polynomic equation with a quadratic regression coefficient of 0.73 , i.e.:

Yield of 1,2,5-trimethylthiophenium hexafluoroantimonate $(\%)=79.73+9.95 \times$ Factor $A+1.07 \times$ Factor $B-4.77 \times$ Factor $C-5.98 \times$ Factor $A^{2}+2.63 \times$ Factor $B^{2}$ $0.234 \times$ Factor $C^{2}-2.10 \times$ Factor $A B-7.45 \times$ Factor $A C+8.40 \times$ Factor $B C$. 
pected salts were obtained. However, when either ethyl or butyl iodide were employed, the number of salts decreased to just a few products. Moreover, no reaction could be detected with the remaining halides.

As Table 2 shows, not all the compounds could be isolated and completely characterized due to different peculiarities of each salt (ring substitution, counterion, chain length; etc.). However, the S-alkylation could be observed by UV-vis spectrometry (Supporting Information, S15). The UV-vis spectra of $S$-methylthiophenium salts were different from those of the starting thiophenes (Table3), changing the absorption wavelength from 230 to around $270 \mathrm{~nm}$. In the case of benzo[ $b]$ thiophenes, the aromatic long wavelength absorptions are destroyed leaving three broad bands at around 220,270 , and $300 \mathrm{~nm}$. It is interesting to remark that neither $S$-alkyl groups nor counterion modify these absorptions, but a small shift is observed due to substituents on the ring.

Table2 S-Alkylation of Different Thiophenes at Optimal Conditions ${ }^{\mathrm{a}}$

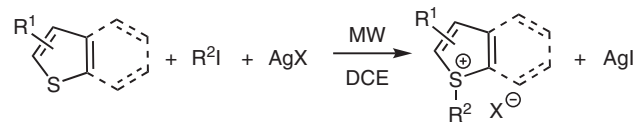

Entry Thiophene

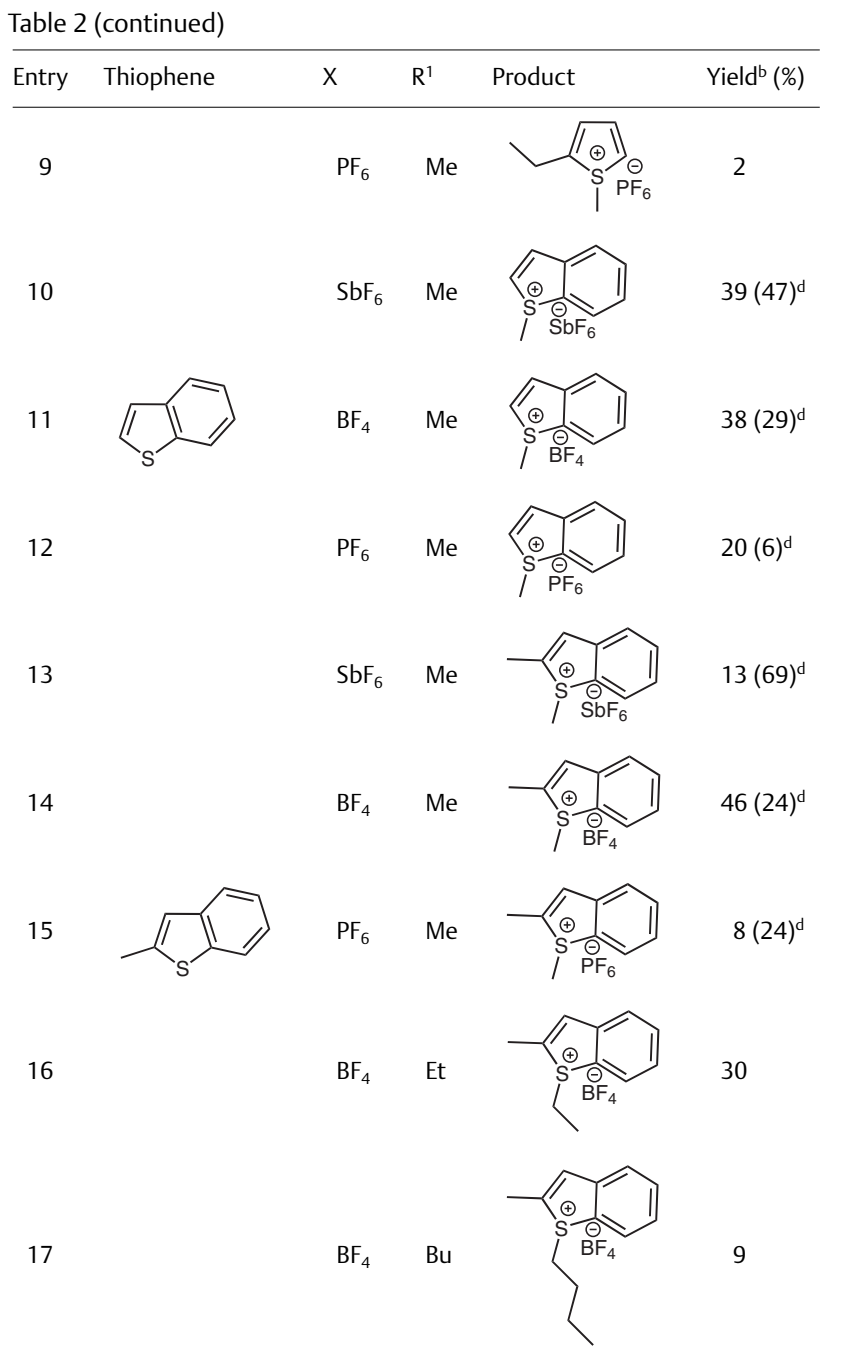

a Reaction conditions: thiophene ( $0.1 \mathrm{mmol}), \mathrm{R}^{2} \mathrm{I}(0.15 \mathrm{mmol}), \mathrm{AgX}$ $(0.1 \mathrm{mmol})$, DCE $(1 \mathrm{~mL})$, microwaves, $200 \mathrm{~W}, 50^{\circ} \mathrm{C}, 25 \mathrm{~min}$.

${ }^{\mathrm{b}} \mathrm{UV}$-Vis quantified in aqueous solution.

c Isolated yields after centrifugal evaporation or lyophilization.

dIsolated yields, precipitation with $\mathrm{Et}_{2} \mathrm{O}$.

The substitution in carbons $\alpha$ to sulfur seems to be of utmost importance, since both 2,5-disubstituted substrates give the highest yields. It is noteworthy that 2-alkyl-5-aromatic-fused rings gave lower yields (Table2, entry 13, 13\%) than the 2,5-dialkyl-substituted thiophene (entry 1,96\%). As shown in Table2 (entries 2, 5, 8, 11, and 14) the performance of different $S$-methyl tetrafluoroborate salts varies according to the substitution in the heterocycle. This might be caused by some steric hindrance or inadequate reaction conditions, since they were optimized for 1,2,5-trimethylthiophenium. On the other hand, the fused aromatic rings apparently afford some extra stability to these compounds. Thus, 1-methylbenzo[b]thiophenium salts (entries 10-12) can be stored in the solid state or in aqueous solution at$18^{\circ} \mathrm{C}$ for 4 months. The same was observed with $1,2-d i-$ 
Table3 UV-vis Spectra of Thiophenes in Ethanol and of Their S-Methyl Tetrafluoroborate Salts in Water

\begin{tabular}{lll}
\hline Thiophene core & & UV-vis $\left(\lambda_{\max }, \mathrm{nm}\right)$ \\
& Thiophene & S-Methylthiophenium tetrafluoroborate \\
\hline 2,5-dimethylthiophene & 236 & $285^{\mathrm{a}}$ \\
2-ethylthiophene & 233 & $230,267^{\mathrm{a}}$ \\
3-methylthiophene & 230 & $237,271^{\text {a }}$ \\
benzo[b]thiophene & $201,226,256,288,296$ & $220,266,297^{\mathrm{a}}$ \\
2-methylbenzo[b]thiophene & $201,227,258,287,297$ & $261,297^{\mathrm{a}}$ \\
\hline
\end{tabular}

${ }^{a}$ Absorption band was used for UV quantification of benzothiophenium salts.

methylbenzo[b]thiophenium tetrafluoroborate (entry 14 , $46 \%$. However, it did not happen with 1,2,5-trimethylthiophenium salts (entries 1-3), which decompose in less than a week and progressively degrade over 3 months in frozen aqueous solution. Moreover, 1,3-dimethylthiophenium tetrafluoroborate (entry 5, 8\%) and 1-methyl-2-ethylthiophenium tetrafluoroborate (entry $8,6 \%$ ) could only be identified in solution through ${ }^{1} \mathrm{H}$ and ${ }^{13} \mathrm{C}$ NMR. When isolation was attempted, only degradation byproducts were observed. To quantify 3-methyl and 2-ethyl salts (entries 4-6 and 7-9, respectively) an alternative approach had to be employed. These salts undergo solvolysis quickly in alcohols giving the starting thiophene. ${ }^{14}$ Taking into account this characteristic, the aqueous salt solution was diluted with excess ethanol, and thiophene, as solvolysis product, was quantified (Supporting Information, S16).

According to literature, ${ }^{38}$ an increase in the volume of anions produces a decrease in their nucleophilic character (the anion could cleave the $S$-alkyl bond). However, the $\mathrm{SbF}_{6}{ }^{-}$anion being the less coordinating one, gives greater quaternization yields (Table2, entries 1, 4, 7, 10, and 13) and more stable products. Following in size $\mathrm{PF}_{6}{ }^{-}$, and against all expectations, its salts are the ones detected and isolated in the lowest yields (Table2, entries 3, 6, 9, 12, and $15)$. On the other hand, $\mathrm{BF}_{4}{ }^{-}$salts give medium yields of relatively stable compounds (Table2, entries 2, 5, 8, 11, and 14). The general order of stability/yield could be explained by a balance between size, polarizability, and superficial charge. The yields of the $\mathrm{SbF}_{6}{ }^{-}$salts obtained are in the order of $30 \%$ and $40 \%$ more than in the case of $\mathrm{BF}_{4}{ }^{-}$salts. In addition, these salts give greater yields (between 55\% and 85\%) than $\mathrm{PF}_{6}{ }^{-}$salts.

The aqueous solubility of $S$-methylbenzo[b]thiophenium salts was estimated by slow addition of a small amount of water to such salts. Thus, the solubilities were $\mathrm{SbF}_{6}{ }^{-}$salt: $5.5 \mathrm{mmol} / \mathrm{L} ; \mathrm{BF}_{4}{ }^{-}$salt: $9.3 \mathrm{mmol} / \mathrm{L}$; and $\mathrm{PF}_{6}{ }^{-}$salt: $9.5 \mathrm{mmol} / \mathrm{L}$. These variations might also explain the differences in chemical yields, both isolated and quantified by UV-vis spectroscopy. Whereas $\mathrm{SbF}_{6}{ }^{-}$salt is too hydrophobic to be extracted efficiently from 1,2-dichloroethane solution (Ta- ble2, entry 10 ), $\mathrm{PF}_{6}{ }^{-}$might be too soluble to precipitate even in diethyl ether (Table2, entry 12), leaving $\mathrm{BF}_{4}{ }^{-}$as medium term (Table2, entry 11 ).

Table2 (entries 14,16 , and 17 ) shows yields obtained for the $S$-alkylation of 2-methylbenzo[b]thiophene employing $\mathrm{AgBF}_{4}$ salt as anion source. It is clear that shorter alkyl chains give better yields; methylation (entry 14) is $36 \%$ more effective than ethylation (entry 16), which, on the other hand, gives a 70\% greater yields than butylation (entry 17). Besides these differences, there are great contrasts regarding stability of compounds. The 1,2-dimethylben$z o[b]$ thiophenium tetrafluoroborate salt is easily isolated by precipitation or evaporation of the solvent and can be stored in solid form for months; while its aqueous solution is stable after freezing. On the contrary, 1-ethyl-2-methylbenzo[b]thiophenium tetrafluoroborate cannot be isolated by precipitation and shows signs of degradation when solvent evaporation is attempted. Like the preceding derivative, its aqueous phase can be stored after freezing, whereas it is hydrolyzed completely at room temperature in less than a week. Finally, 1-butyl-2-methylbenzo[b]thiophenium tetrafluoroborate could not be isolated as it decomposes completely during the removal of the solvent. Its aqueous solution is stable enough for $24 \mathrm{~h}$ only, although it could be stored for two weeks after freezing without appreciable decomposition.

A differential scanning calorimetry (DSC) at $5^{\circ} \mathrm{C} / \mathrm{min}$ (Figure 3) was carried out for those salts obtained in acceptable yields, namely 1 -methylbenzo[b]thiophenium hexafluoroantimonate, 1,2-dimethylbenzo[b]thiophenium hexafluoroantimonate, and 1,2-dimethylbenzo[b]thiophenium tetrafluoroborate.

1,2-Dimethylbenzo[b]thiophenium tetrafluoroborate showed a classical ionic liquid behavior (Figure 3 ). The crystals melted at $79^{\circ} \mathrm{C}$ with an endothermic transition of $15.8 \mathrm{~kJ} / \mathrm{mol}$, and then it did not solidify in the studied range. A second heating did not show any phase transitions either. 1,2-Dimethylbenzo[b]thiophenium hexafluoroantimonate had a similar behavior (Figure 3); it started melting at around $93^{\circ} \mathrm{C}$ with an enthalpy of $24.6 \mathrm{~kJ} / \mathrm{mol}$. Cooling down did not show solidification in the studied range, although further heating showed a broad exothermic transition cor- 
responding to recrystallization of the compound at around $32^{\circ} \mathrm{C}$, followed by melting at $67^{\circ} \mathrm{C}$, indicating that this salt recrystallized in a different structure.

Finally, 1-methylbenzo[b]thiophenium hexafluoroantimonate had a different behavior (Figure 3). In the first heating cycle, it showed two endothermic transitions. At $64^{\circ} \mathrm{C}$ there was a first transition phase with an enthalpy of $12.4 \mathrm{~kJ} / \mathrm{mol}$ and the final melting occurred at $111^{\circ} \mathrm{C}$ with a smaller enthalpy of $6 \mathrm{~kJ} / \mathrm{mol}$. This seemed to indicate that between these temperatures there was a mesophase region, probably a liquid crystalline one. ${ }^{39}$ During the cooling cycle there was only a sharp transition at around $80^{\circ} \mathrm{C}$ with an enthalpy of $-5 \mathrm{~kJ} / \mathrm{mol}$, which was the reverse transition of the melting at $111^{\circ} \mathrm{C}$. The salt did not resolidify in this range. The second heating cycle showed a broad small endothermic transition at $103^{\circ} \mathrm{C}$.

All these data agree with the typical profile expected for ionic liquids having melting points below $100^{\circ} \mathrm{C}$, and an extended super-cooling region.

In summary, the microwave energy has the ability to give the appropriate conditions, in a short time, for producing different thiophenium salts from a thiophene ring and an alkylating agent. Moreover, the reaction time is the significant variable in the experimental design. It is important to mention that alkyl substitution in carbons $\alpha$ to the sulfur atom gives rise to the highest yields. Furthermore, the chain length in the S-alkylation plays an important role in obtaining compounds with high yields and stability. In this sense, the shorter chains give better yields and stability.

For salts, the role played by the anion is twofold: on the one hand it contributes to the stability of the ionic liquid and therefore greater yields are observed. On the other hand, it tunes the solubility in the reaction medium, which affects the isolation efficiency. The observed order is $\mathrm{SbF}_{6}>\mathrm{PF}_{6}>\mathrm{BF}_{4}$. A differential scanning calorimetry (DSC) study for the stable salts, showed that such compounds are effectively ionic liquids with melting points lower than $100^{\circ} \mathrm{C}$, thus making them valuable materials for future studies and opportunities. In addition, a full theoretical analysis on the mechanistic pathway and structural relationships is currently under way and will be published in due course.

Reagents were obtained from commercial sources and employed as received. $\mathrm{AgBF}_{4}$ and $\mathrm{AgPF}_{6}$ were prepared according to literature, ${ }^{40}$ but instead of recrystallization, product was washed repeatedly with $\mathrm{CH}_{2}-$ $\mathrm{Cl}_{2}$; AgNTf $_{2}$ was prepared by reaction of silver oxide with trifluoromethanesulfonimide, which was obtained from its lithium salt. ${ }^{41}$ Organic solvents were distilled and dried according to standard procedures, prior to use. Deionized water (type II quality) was obtained with a Millipore Elix 10 UV Water Purification System. ${ }^{1} \mathrm{H}$ and ${ }^{13} \mathrm{C}$ NMR spectra were recorded on a Bruker ARX $300\left(300.1 \mathrm{MHz}\right.$ for ${ }^{1} \mathrm{H}$, $75.5 \mathrm{MHz}$ for ${ }^{13} \mathrm{C}$ ) using $\mathrm{D}_{2} \mathrm{O}$ or $\mathrm{CDCl}_{3}$ as solvents. The UV-visible spectra were recorded in a Carey 60 version 2.0 instrument. A quartz 5-mL
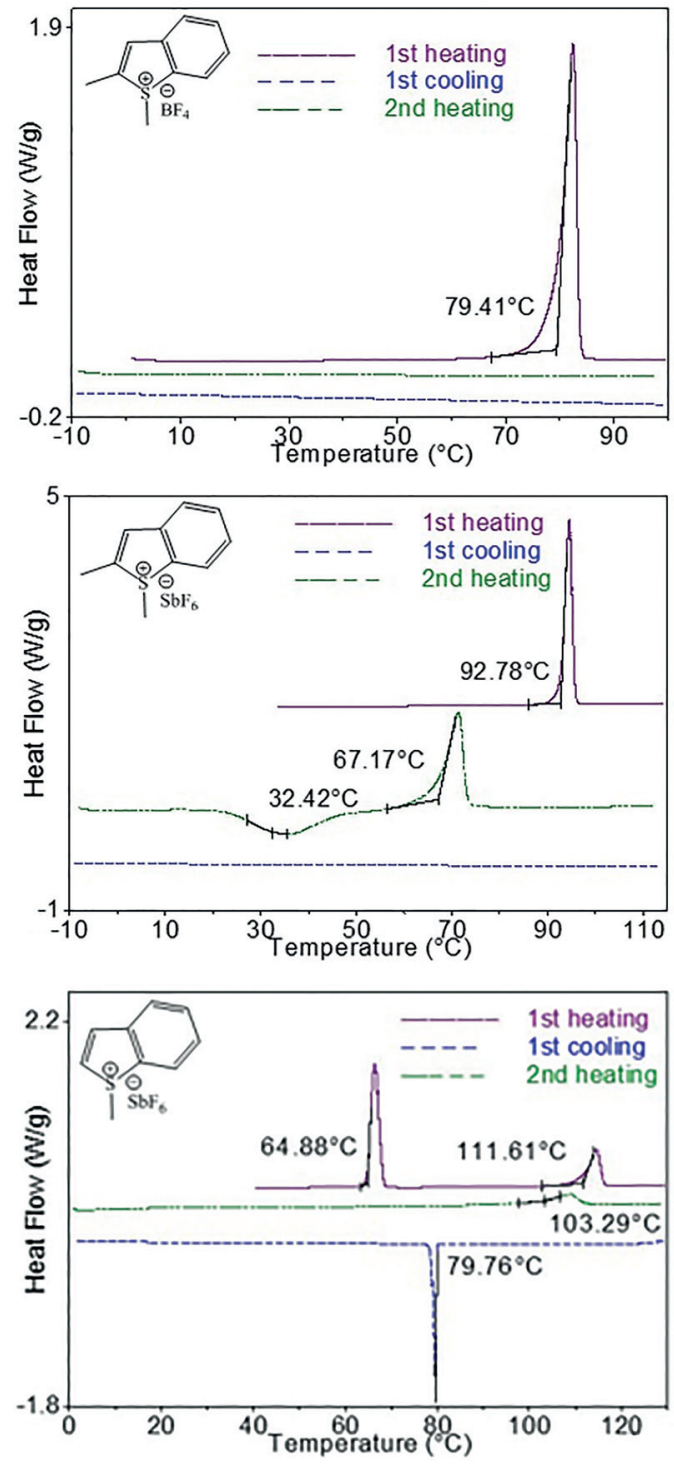

Figure 3 DSC scans: 1,2-dimethylbenzo[b]thiophenium tetrafluoroborate, 1,2-dimethylbenzo[ $b$ ]thiophenium hexafluoroantimonate, 1methylbenzo[ $b$ thiophenium hexafluoroantimonate; heating rate $=$ $5^{\circ} \mathrm{C} / \mathrm{min}$, exothermic transitions are recorded with negative heat flow

cell was chosen for the measurements. The Analytical Services of the Universidad Nacional del Sur performed the $\mathrm{C}, \mathrm{H}$, and $\mathrm{S}$ analyses with an Exeter Analytical Inc. CE-440 microanalyzer. The DSC measurements were performed in a TA Instrument Q20 V23 with $\mathrm{N}_{2}$ as protection gas. Approximately $3 \mathrm{mg}$ of sample were analyzed in standard aluminum pans. The scans are carried out at $5^{\circ} \mathrm{C} / \mathrm{min}$ rate for heating and subsequent cooling, and data are displayed so exothermic transitions occur at negative heat flow and endothermic ones are positive. Displayed temperatures (tagged in the graphs) correspond to the onset of the respective transition. Microwave (MW) assisted reactions were carried out from 0 to $300 \mathrm{~W}$, programmable in $1-\mathrm{W}$ increments, in the CEM Discover Benchmate oven with a $10-\mathrm{mL}$ closed system 
vessel. The temperature system located in the instrument cavity is revised by a calibrated infrared sensor, which monitors and controls the temperature conditions of the reaction vessel (programmable from $\left.25-250^{\circ} \mathrm{C}\right)$.

1,2,5-Trimethylthiophenium Hexafluoroantimonate; Typical Procedure for Thermal Conditions

2,5-Dimethylthiophene $(67.0 \mathrm{mg}, 0.6 \mathrm{mmol})$ was stirred along with $\mathrm{AgSbF}_{6}(171.6 \mathrm{mg}, 0.5 \mathrm{mmol})$ in DCE $(1 \mathrm{~mL})$ at $0^{\circ} \mathrm{C}$ until the system was cool. Afterwards, MeI $(255.0 \mathrm{mg}, 1.8 \mathrm{mmol})$ was added in one portion. The reaction vessel was hermetically closed and the reaction was magnetically stirred in the dark for $24 \mathrm{~h}$ at r.t. After completion the precipitate was filtered off and washed with DCE. The supernatant was extracted with $\mathrm{D}_{2} \mathrm{O}$ to analyze the extract by NMR directly. Extraction was completed with miliQ water $(3 \times 1 \mathrm{~mL})$. Weighting and additions of reagents were carried out under infrared light to minimize humidity. Aqueous solutions of salt were evaporated and dried with either freeze-drying or with a centrifugal evaporator at r.t. The salt was obtained as a white solid; yield: $18.0 \mathrm{mg}(0.0515 \mathrm{mmol}, 10 \%) ; \mathrm{mp}$ $45-55^{\circ} \mathrm{C}$ (decomp.)

${ }^{1} \mathrm{H}$ NMR (300MHz, $\mathrm{D}_{2} \mathrm{O}$ ): $\delta=6.97$ (s, $2 \mathrm{H}$ ), 3.19 (s, $\left.3 \mathrm{H}\right), 2.39$ (s, $\left.6 \mathrm{H}\right)$.

${ }^{13} \mathrm{C}$ NMR $\left(75 \mathrm{MHz}, \mathrm{D}_{2} \mathrm{O}\right): \delta=141.3,136.7,25.9,12.8$.

UV-vis: $\lambda_{\max }=285 \mathrm{~nm}$.

Anal. Calcd for $\mathrm{C}_{7} \mathrm{H}_{11} \mathrm{~F}_{6} \mathrm{SSb}$ : C, 23.16; H, 3.05; S, 8.83.Found: C, 23.21; $\mathrm{H}, 3.11 ; \mathrm{S}, 8.79$.

The solid was dissolved in distilled water to build a calibration curve. Linear range $0.064 \mathrm{mg} / \mathrm{mL}$ to $0.32 \mathrm{mg} / \mathrm{mL}$, slope 5.735 , origin coordinate 0.031 , and correlation coefficient 0.9999 were obtained (see the Supporting Information, S16). This curve was employed to quantify the reactions of experimental design.

\section{1-Methylbenzo[b]thiophenium Hexafluoroantimonate; Typical Procedure for Thermal Conditions with Modified Workup}

The reaction was carried out as for 1,2,5-trimethylthiophenium hexafluoroantimonate in thermal synthesis, although the workup was modified: the supernatant was separated and the precipitate washed with DCE. To the combined organic layers $\mathrm{Et}_{2} \mathrm{O}$ was added and the bottom of the vessel was scratched until opalescence appeared. The system was cooled overnight at $-18^{\circ} \mathrm{C}$ until no more precipitate appeared. The supernatant was removed and the solid was washed with dry $\mathrm{Et}_{2} \mathrm{O}$ and dried under vacuum. The salt was obtained as white needles; yield: $121 \mathrm{mg}(0.31 \mathrm{mmol}, 63 \%)$; $\mathrm{mp} 64-65^{\circ} \mathrm{C}$; water solubility: $5.5 \mathrm{mmol} \mathrm{L}^{-1}\left(2.13 \mathrm{~g} \mathrm{~L}^{-1}\right)$.

${ }^{1} \mathrm{H} \mathrm{NMR}\left(300 \mathrm{MHz}, \mathrm{D}_{2} \mathrm{O}\right): \delta=8.15\left(\mathrm{~d},{ }^{3} J_{\mathrm{H}-\mathrm{H}}=7.6 \mathrm{~Hz}, 1 \mathrm{H}\right), 7.95\left(\mathrm{t},{ }^{3} J_{\mathrm{H}-\mathrm{H}}=\right.$ $7.2 \mathrm{~Hz}, 2 \mathrm{H}), 7.83\left(\mathrm{t},{ }^{3} J_{\mathrm{H}-\mathrm{H}}=7.6 \mathrm{~Hz}, 1 \mathrm{H}\right), 7.73\left(\mathrm{t},{ }^{3} J_{\mathrm{H}-\mathrm{H}}=7.8 \mathrm{~Hz}, 1 \mathrm{H}\right), 7.39$ $\left(\mathrm{d},{ }^{3} J_{\mathrm{H}-\mathrm{H}}=5.7 \mathrm{~Hz}, 1 \mathrm{H}\right), 3.27(\mathrm{~s}, 3 \mathrm{H})$.

${ }^{13} \mathrm{C}$ NMR $\left(75 \mathrm{MHz}, \mathrm{D}_{2} \mathrm{O}\right): \delta=142.2,135.1,133.3,130.5,127.5,127.4$, 126.3, 123.3, 30.6.

UV-vis $\left(\mathrm{H}_{2} \mathrm{O}\right) \lambda_{\max }=220,266,297 \mathrm{~nm}$.

Anal. Calcd for $\mathrm{C}_{9} \mathrm{H}_{9} \mathrm{~F}_{6} \mathrm{SSb}$ : C, 28.08; H, 2.36; S, 8.33.Found: C, 28.15; $\mathrm{H}, 2.40 ; \mathrm{S}, 8.24$.

\section{1,2,5-Trimethylthiophenium Hexafluoroantimonate; Typical Pro-} cedure for Microwave-Assisted Synthesis

In a 10-mL closed system microwave vessel, 2,5-dimethylthiophene (11.2 mg, $0.1 \mathrm{mmol}$ ), MeI (21.5mg, $0.15 \mathrm{mmol}$ ), and $\mathrm{AgSbF}_{6}(34.4 \mathrm{mg}$, $0.1 \mathrm{mmol}$ ) were added to dry DCE under infrared light. The vessel was closed and the microwave-assisted reaction was carried out with the following fixed conditions: mode, sps; $\Delta$ temperature, $1{ }^{\circ} \mathrm{C}$; stirring, high; max power, off. The reaction temperature was maintained at $50^{\circ} \mathrm{C}$ and $200 \mathrm{~W}$ of power for $25 \mathrm{~min}$. The workup was the same as in thermal conditions; yield: $26.0 \mathrm{mg}(0.074 \mathrm{mmol}, 74 \%)$. The aqueous phase was brought to volume for UV-visible quantification. Some replicates were also evaporated with centrifugal evaporation to isolate the product and assess its stability. Alternatively, extraction was carried out with an aliquot of $\mathrm{D}_{2} \mathrm{O}$ for direct NMR characterization.

\section{1,2,5-Trimethylthiophenium Tetrafluoroborate}

White solid; yield: $7.7 \mathrm{mg}(0.036 \mathrm{mmol}, 36 \%) ; \mathrm{mp} 39-42^{\circ} \mathrm{C}$. ${ }^{1} \mathrm{H}$ NMR (300MHz, $\left.\mathrm{D}_{2} \mathrm{O}\right): \delta=6.99(\mathrm{~s}, 2 \mathrm{H}), 3.21(\mathrm{~s}, 3 \mathrm{H}), 2.41(\mathrm{~s}, 6 \mathrm{H})$.

${ }^{13} \mathrm{C}$ NMR $\left(75 \mathrm{MHZ}, \mathrm{D}_{2} \mathrm{O}\right): \delta=140.5,135.9,48.0,12.0$.

UV-vis: $\lambda_{\max }=285 \mathrm{~nm}$.

Anal. Calcd for $\mathrm{C}_{7} \mathrm{H}_{11} \mathrm{BF}_{4} \mathrm{~S}$ : C, 39.28; H, 5.18; S, 14.98.Found: C, 39.45; H, 5.25; S, 15.02 .

\section{1,2,5-Trimethylthiophenium Hexafluorophosphate}

UV-vis quantified: $30 \%$.

${ }^{1} \mathrm{H}$ NMR (300MHz, $\left.\mathrm{D}_{2} \mathrm{O}\right): \delta=6.97$ (s, $2 \mathrm{H}$ ), 3.19 (s, $\left.3 \mathrm{H}\right), 2.39$ (s, $\left.6 \mathrm{H}\right)$.

UV-vis: $\lambda_{\max }=285 \mathrm{~nm}$.

\section{1,3-Dimethylthiophenium Tetrafluoroborate}

UV-vis quantified: $8 \%$.

${ }^{1} \mathrm{H}$ NMR $\left(300 \mathrm{MHz}, \mathrm{D}_{2} \mathrm{O}\right): \delta=7.51\left(\mathrm{~d},{ }^{3} \mathrm{H}_{\mathrm{H}-\mathrm{H}}=2.6 \mathrm{~Hz}, 1 \mathrm{H}\right), 7.43\left(\mathrm{~d},{ }^{3} J_{\mathrm{H}-\mathrm{H}}=\right.$ $5.5 \mathrm{~Hz}, 1 \mathrm{H}), 7.12(\mathrm{~s}, 1 \mathrm{H}), 3.18(\mathrm{~s}, 3 \mathrm{H}), 2.31(\mathrm{~s}, 3 \mathrm{H})$.

${ }^{13} \mathrm{C}$ NMR $\left(75 \mathrm{MHz}, \mathrm{D}_{2} \mathrm{O}\right): \delta=144.8,128.5,120.4,48.9,16.0$.

UV-vis: $\lambda_{\max }=237,271 \mathrm{~nm}$.

\section{1,3-Dimethylthiophenium Hexafluoroantimonate}

UV-vis quantified: $21 \%$. This salt could not be isolated because it rapidly decomposes.

\section{1,3-Dimethylthiophenium Hexafluorophosphate}

UV-vis quantified: $6 \%$. This salt could not be isolated because it rapidly decomposes.

\section{2-Ethyl-1-methylthiophenium Hexafluoroantimonate}

UV-vis quantified: $10 \%$. This salt could not be isolated because it rapidly decomposes.

\section{2-Ethyl-1-methylthiophenium Hexafluorophosphate}

UV-vis quantified: $2 \%$. This salt could not be isolated because it rapidly decomposes.

\author{
2-Ethyl-1-methylthiophenium Tetrafluoroborate \\ UV-vis quantified: $6 \%$. \\ ${ }^{1} \mathrm{H}$ NMR $\left(300 \mathrm{MHz}, \mathrm{D}_{2} \mathrm{O}\right): \delta=7.45\left(\mathrm{dd},{ }^{3} \mathrm{~J}_{\mathrm{H}-\mathrm{H}}=5.7,3.2 \mathrm{~Hz}, 1 \mathrm{H}\right), 7.39(\mathrm{~d}$, \\ $\left.3 J_{\mathrm{H}-\mathrm{H}}=5.6 \mathrm{~Hz}, 1 \mathrm{H}\right), 7.15(\mathrm{~s}, 1 \mathrm{H}), 3.21(\mathrm{~s}, 3 \mathrm{H}), 2.97-2.63(\mathrm{~m}, 2 \mathrm{H}), 1.30$ \\ $\left(\mathrm{t},{ }^{3} \mathrm{~J}_{\mathrm{H}-\mathrm{H}}=7.4 \mathrm{~Hz}, 3 \mathrm{H}\right)$. \\ ${ }^{13} \mathrm{C} \mathrm{NMR}\left(75 \mathrm{MHz}, \mathrm{CDCl}_{3}\right): \delta=142.7,134.0,126.1,48.9,21.0,12.6$. \\ UV-vis: $\lambda_{\max }=261,297 \mathrm{~nm}$.
}

\section{1-Methylbenzo[b]thiophenium Tetrafluoroborate}

White needles; yield: $18 \mathrm{mg}$ (0.047 mmol, 47\%); mp 65-66 ${ }^{\circ} \mathrm{C}$; water solubility at $25^{\circ} \mathrm{C}: 9.3 \mathrm{mmol} \mathrm{L}^{-1}\left(2.2 \mathrm{~g} \mathrm{~L}^{-1}\right)$. 
${ }^{1} \mathrm{H} \mathrm{NMR}\left(300 \mathrm{MHz}, \mathrm{CDCl}_{3}\right): \delta=8.47\left(\mathrm{~d},{ }^{3} J_{\mathrm{H}-\mathrm{H}}=8.3 \mathrm{~Hz}, 1 \mathrm{H}\right), 7.86\left(\mathrm{~d},{ }^{3} J_{\mathrm{H}-\mathrm{H}}=\right.$ 7.1 Hz, $1 \mathrm{H}), 7.83-7.64(\mathrm{~m}, 4 \mathrm{H}), 3.46(\mathrm{~s}, 3 \mathrm{H})$.

${ }^{13} \mathrm{C} \mathrm{NMR}\left(75 \mathrm{MHz}, \mathrm{CDCl}_{3}\right): \delta=141.1,140.7,133.6,133.0,131.2,128.0$, 127.1, 125.5, 31.9.

UV-vis: $\lambda_{\max }=220,266,297 \mathrm{~nm}$.

Anal. Calcd for $\mathrm{C}_{9} \mathrm{H}_{9} \mathrm{BF}$ S: C, 45.80; H, 3.84; S, 13.58.Found: C, 46.11; H, 4.02; S, 13.76 .

\section{1-Methylbenzo[b]thiophenium Hexafluorophosphate}

Slightly yellow solid; yield: $1.76 \mathrm{mg}(0.006 \mathrm{mmol}, 6 \%)$;p $66-68{ }^{\circ} \mathrm{C}$; water solubility at $25^{\circ} \mathrm{C}: 9.9 \mathrm{mmol} \mathrm{L}^{-1}\left(2.85 \mathrm{~g} \mathrm{~L}^{-1}\right)$.

${ }^{1} \mathrm{H} \mathrm{NMR}\left(300 \mathrm{MHz}, \mathrm{D}_{2} \mathrm{O}\right): \delta=8.18\left(\mathrm{~d},{ }^{3} J_{\mathrm{H}-\mathrm{H}}=7.9 \mathrm{~Hz}, 1 \mathrm{H}\right), 7.96\left(\mathrm{t},{ }^{3} J_{\mathrm{H}-\mathrm{H}}=\right.$ $7.3 \mathrm{~Hz}, 2 \mathrm{H}), 7.87\left(\mathrm{t},{ }^{3} J_{\mathrm{H}-\mathrm{H}}=7.5 \mathrm{~Hz}, 1 \mathrm{H}\right), 7.74\left(\mathrm{t},{ }^{3} J_{\mathrm{H}-\mathrm{H}}=7.7 \mathrm{~Hz}, 1 \mathrm{H}\right), 7.41$ $\left(\mathrm{d},{ }^{3} \mathrm{H}_{\mathrm{H}}=5.7 \mathrm{~Hz}, 1 \mathrm{H}\right), 3.28(\mathrm{~s}, 3 \mathrm{H})$.

UV-vis: $\lambda_{\max }=220,265,297 \mathrm{~nm}$.

Anal. Calcd for $\mathrm{C}_{9} \mathrm{H}_{9} \mathrm{~F}_{6}$ PS: C, 36.74; $\mathrm{H}, 3.08$; $\mathrm{S}, 10.90$.Found: $\mathrm{C}, 37.01$; H, 3.21; S, 11.05 .

\section{1,2-Dimethylbenzo[b]thiophenium Hexafluoroantimonate}

White solid; yield: $26.7 \mathrm{mg}(0.067 \mathrm{mmol}, 69 \%) ; \mathrm{mp} 93-94^{\circ} \mathrm{C}$.

${ }^{1} \mathrm{H} \mathrm{NMR}\left(300 \mathrm{MHz}, \mathrm{D}_{2} \mathrm{O}\right): \delta=8.08\left(\mathrm{~d},{ }^{3} \mathrm{~J}_{\mathrm{H}-\mathrm{H}}=8.0 \mathrm{~Hz}, 1 \mathrm{H}\right), 7.87-7.74(\mathrm{~m}$, $2 \mathrm{H}), 7.64\left(\mathrm{t},{ }^{3} \mathrm{H}_{\mathrm{H}-\mathrm{H}}=7.6 \mathrm{~Hz}, 1 \mathrm{H}\right), 7.50(\mathrm{~s}, 1 \mathrm{H}), 3.27(\mathrm{~s}, 3 \mathrm{H}), 2.51(\mathrm{~s}, 3 \mathrm{H})$.

${ }^{13} \mathrm{C}$ NMR $\left(75 \mathrm{MHz}, \mathrm{D}_{2} \mathrm{O}\right): \delta=141.9,137.8,136.3,133.4,129.4,126.4$, 126.3, 29.4, 13.1 .

UV-vis: $\lambda_{\max }=261,298 \mathrm{~nm}$.

Anal. Calcd for $\mathrm{C}_{10} \mathrm{H}_{11} \mathrm{~F}_{6} \mathrm{SSb}$ : C, 30.10; H, 2.78; S, 8.03.Found: C, 30.23; $\mathrm{H}, 2.84 ; \mathrm{S}, 8.11$.

\section{1,2-Dimethylbenzo[b]thiophenium Tetrafluoroborate}

White solid; yield: $6.0 \mathrm{mg}(0.024 \mathrm{mmol}, 24 \%) ; \mathrm{mp} 79-81^{\circ} \mathrm{C}$.

${ }^{1} \mathrm{H}$ NMR $\left(300 \mathrm{MHz}, \mathrm{D}_{2} \mathrm{O}\right): \delta=8.11\left(\mathrm{~d},{ }^{3} \mathrm{~J}_{\mathrm{H}-\mathrm{H}}=7.9 \mathrm{~Hz}, 1 \mathrm{H}\right), 7.85-7.80(\mathrm{~m}$, $2 \mathrm{H}), 7.64\left(\mathrm{t},{ }^{3} \mathrm{H}_{\mathrm{H}-\mathrm{H}}=7.6 \mathrm{~Hz}, 1 \mathrm{H}\right), 7.52(\mathrm{~s}, 1 \mathrm{H}), 3.30(\mathrm{~s}, 3 \mathrm{H}), 2.54(\mathrm{~s}, 3 \mathrm{H})$.

${ }^{13} \mathrm{C}$ NMR $\left(75 \mathrm{MHZ}, \mathrm{D}_{2} \mathrm{O}\right): \delta=141.9,137.9,136.3,133.5,132.4,129.4$, $126.4,126.3,29.4,13.1$.

UV-vis: $\lambda_{\max }=261,297 \mathrm{~nm}$.

Anal. Calcd for $\mathrm{C}_{10} \mathrm{H}_{11} \mathrm{BF}$ S: C, 48.03; H, 4.43; S, 12.82.Found: C, 48.11; $\mathrm{H}, 4.48 ; \mathrm{S}, 12.90$.

\section{1,2-Dimethylbenzo[b]thiophenium Hexafluorophosphate}

Slightly yellow powder; yield: $7.4 \mathrm{mg}(0.024 \mathrm{mmol}, 24 \%)$; $\mathrm{mp} 98-$ $101^{\circ} \mathrm{C}$.

${ }^{1} \mathrm{H}$ NMR $\left(300 \mathrm{MHz}, \mathrm{D}_{2} \mathrm{O}\right): \delta=8.10\left(\mathrm{~d},{ }^{3} J_{\mathrm{H}-\mathrm{H}}=8.8 \mathrm{~Hz}, 1 \mathrm{H}\right), 7.80\left(\mathrm{q},{ }^{3} J_{\mathrm{H}-\mathrm{H}}=\right.$ $8.8 \mathrm{~Hz}, 2 \mathrm{H}), 7.65\left(\mathrm{t},{ }^{3} J_{\mathrm{H}-\mathrm{H}}=7.6 \mathrm{~Hz}, 1 \mathrm{H}\right), 7.51(\mathrm{~s}, 1 \mathrm{H}), 3.28(\mathrm{~s}, 3 \mathrm{H}), 2.53$ (s, $3 \mathrm{H})$.

${ }^{13} \mathrm{C}$ NMR $\left(75 \mathrm{MHz}, \mathrm{D}_{2} \mathrm{O}\right): \delta=141.9,137.9,136.3,133.5,132.4,129.4$, 126.4, 126.3, 29.4, 13.1 .

UV-vis: $\lambda_{\max }=261,297 \mathrm{~nm}$

Anal. Calcd for $\mathrm{C}_{10} \mathrm{H}_{11} \mathrm{~F}_{6}$ PS: C, 38.97; H, 3.60; S, 10.40.Found: C, 39.05; H, 3.69; S, 10.56 .

\section{1-Ethyl-2-methylbenzo[b]thiophenium Tetrafluoroborate}

UV-vis quantified: $30 \%$.
${ }^{1} \mathrm{H} \mathrm{NMR}\left(300 \mathrm{MHz}, \mathrm{D}_{2} \mathrm{O}\right): \delta=8.04\left(\mathrm{~d},{ }^{3} \mathrm{~J}_{\mathrm{H}-\mathrm{H}}=8.0 \mathrm{~Hz}, 1 \mathrm{H}\right), 7.79\left(\mathrm{~m},{ }^{3} J_{\mathrm{H}-\mathrm{H}}=\right.$ $7.6 \mathrm{~Hz}, 2 \mathrm{H}), 7.64\left(\mathrm{t},{ }^{3} \mathrm{~J}_{\mathrm{H}-\mathrm{H}}=7.4 \mathrm{~Hz}, 1 \mathrm{H}\right), 7.57(\mathrm{~s}, 1 \mathrm{H}), 4.02\left(\mathrm{dq},{ }^{3} J_{\mathrm{H}-\mathrm{H}}=\right.$ $14.3,7.2 \mathrm{~Hz}, 1 \mathrm{H}), 3.83\left(\mathrm{dq},{ }^{3} \mathrm{H}_{\mathrm{H}-\mathrm{H}}=14.2,7.1 \mathrm{~Hz}, 1 \mathrm{H}\right), 2.47(\mathrm{~s}, 3 \mathrm{H}), 0.92$ $\left(\mathrm{t}, 3_{\mathrm{H}-\mathrm{H}}=7.0 \mathrm{~Hz}, 3 \mathrm{H}\right)$.

${ }^{13} \mathrm{C}$ NMR $\left(75 \mathrm{MHz}, \mathrm{D}_{2} \mathrm{O}\right): \delta=143.3,138.2,133.5,133.4,129.3,128.3$, $126.9,126.1,39.8,13.4,5.7$.

UV-vis: $\lambda_{\max }=261,297 \mathrm{~nm}$.

\section{1-Butyl-2-methylbenzo[b]thiophenium Tetrafluoroborate}

UV-vis quantified: $9 \%$.

${ }^{1} \mathrm{H}$ NMR $\left(300 \mathrm{MHz}, \mathrm{D}_{2} \mathrm{O}\right): \delta=8.06\left(\mathrm{~d},{ }^{3} J_{\mathrm{H}-\mathrm{H}}=8.0 \mathrm{~Hz}, 1 \mathrm{H}\right), 7.94-7.74(\mathrm{~m}$, $2 \mathrm{H}), 7.65\left(\mathrm{t},{ }^{3} J_{\mathrm{H}-\mathrm{H}}=7.4 \mathrm{~Hz}, 1 \mathrm{H}\right), 7.57(\mathrm{~s}, 1 \mathrm{H}), 3.59\left(\mathrm{t},{ }^{3} J_{\mathrm{H}-\mathrm{H}}=6.6 \mathrm{~Hz}, 2 \mathrm{H}\right)$, $2.50(\mathrm{~s}, 3 \mathrm{H}), 1.57-1.46(\mathrm{~m}, 2 \mathrm{H}), 1.40-1.28(\mathrm{~m}, 2 \mathrm{H}), 0.89\left(\mathrm{t}, 3_{\mathrm{H}-\mathrm{H}}=\right.$ $7.4 \mathrm{~Hz}, 3 \mathrm{H})$.

UV-vis: $\lambda_{\max }=260,297 \mathrm{~nm}$.

\section{Acknowledgment}

This work was partially supported by CONICET, ANPCyT, and the Universidad Nacional del Sur, Bahía Blanca, Argentina. CONICET is gratefully acknowledged for a Research fellowship to M.A.S.The authors thank Professor Pedro Cintas for helpful discussion and comments. We thank the Empresa Neuquina de Servicios de Ingeniería S.E., Argentine, for supplying $\mathrm{D}_{2} \mathrm{O}$.

\section{Supporting Information}

Supporting information for this article is available online at https://doi.org/10.1055/s-0037-1609934.

\section{References}

(1) Rio Declaration on Environment and Development (1992); United Nations: Rio de Janeiro, 1992, http://www.un.org/documents/ga/conf151/aconf15126-1annex1.htm.

(2) Anastas, P. T.; Warner, J. C. Green Chemistry: Theory and Practice; Oxford University Press: Oxford, 2000.

(3) Khadilkar, B. M.; Rebeiro, G. L. Org. Process Res. Dev. 2002, 6, 826.

(4) Burns, C. T.; Lee, S.; Seifert, S. M.; Firestone, A. Polym. Adv. Technol. 2008, 10, 1369.

(5) Martínez-Palou, R. Mol. Diversity 2010, 14, 3.

(6) Vidal, L.; Psillakis, E.; Domini, C. E.; Grané, N.; Marken, F.; Canals, A. Anal. Chim. Acta 2007, 584, 189.

(7) Martins, M. A.; Frizzo, C. P.; Moreira, D. N.; Zanatta, N.; Bonacorso, H. G. Chem. Rev. 2008, 108, 2015.

(8) Zhang, Y.; Lee, H. K. Anal. Chim. Acta 2012, 750, 120.

(9) Tan, Z. Q.; Liu, J. F.; Pang, L. TrAC, Trends Anal. Chem. 2012, 39, 218.

(10) Anderson, J. L.; Armstrong, D. W.; Wei, G.-T. Anal. Chem. 2006, 2892.

(11) Welton, T. Chem. Rev. 1999, 99, 2071.

(12) Del Sesto, R. E.; McCleskey, T. M.; Macomber, C.; Ott, K. C.; Koppisch, A. T.; Baker, G. A.; Burrell, A. K. Thermochim. Acta 2009, 491, 118 .

(13) Endres, F.; El Abedin, S. Z. Phys. Chem. Chem. Phys. 2006, 8, 2101.

(14) Acheson, R. M.; Harrison, D. R. J. Chem. Soc. C 1970, 1764.

(15) Heldeweg, R. F.; Hogeveen, H. Tetrahedron Lett. 1974, 15, 75. 
(16) Lee, S. S.; Lee, T. Y.; Choi, D. S.; Lee, J. S.; Chung, Y. K.; Lee, S. W.; Lah, M. S. Organometallics 1997, 16, 1749.

(17) Schiel, M. A.; Domini, C. E.; Chopa, A. B.; Silbestri, G. F. Arabian J. Chem. 2016, in press; DOI: 10.1016/j.arabjc.2016.11.002.

(18) de la Hoz, A.; Diaz-Ortiz, A.; Moreno, A. Chem. Soc. Rev. 2005, 34, 164.

(19) Rinaldi, L.; Carnaroglio, D.; Rotolo, L.; Cravotto, G. J. Chem. 2015, 879531; DOI: $\quad 10.1155 / 2015 / 879531$; http://www.hindawi.com/journals/jchem.

(20) Gawande, M. B.; Shelke, S. N.; Zboril, R.; Varma, R. S. Acc. Chem. Res. 2014, 47, 1338.

(21) Álvarez, M. B.; Domini, C. E.; Silbestri, G. F. Signpost Open Access J. Org. Biomol. Chem. 2015, 3, 44; http://signpostejournals.com/ejournals/organic_and_biomolecular_chemistry/Home.aspx.

(22) Roberts, B. A.; Strauss, C. R. Acc. Chem. Res. 2005, 38, 653.

(23) Namboodiri, V. V.; Varma, R. S. Tetrahedron Lett. 2002, 43, 5381.

(24) Namboodiri, V. V.; Varma, R. S. Chem. Commun. 2002, 342.

(25) Berthold, H.; Schotten, T.; Hönig, H. Synthesis 2002, 1607.

(26) González-Prieto, R.; Herrero, S.; Jiménez-Aparicio, R.; Morán, E.; Prado-Gonjal, J.; Priego, J. L.; Schmidt, R. Microwave Chemistry; Cravotto, G.; Carnaroglio, D., Ed.; Walter de Gruyter: Berlin, 2017, 225-247.

(27) We wondered about the effect of MW on ionic materials. This is a complex issue that can be related to the effect of MW on electrolytes. Owing to their strong localized electric fields, ions influence the solvent's molecular interactions. In some cases, the presence of ions tends to decrease the real part of the dielectric permittivity, thus increasing the temperature. For a detailed discussion see: Stuerga, D. Microwaves in Organic Synthesis; De la Hoz, A.; Loupy, A., Ed.; Wiley-VCH: Weinheim, 2012, 1-56.

(28) Horikoshi, S.; Serpone, N. Microwaves in Organic Synthesis; De la Hoz, A.; Loupy, A., Ed.; Wiley-VCH: Weinheim, 2012, 377.

(29) Candioti, L. V.; De Zan, M. M.; Cámara, M. S.; Goicoechea, H. C. Talanta 2014, 124, 123.

(30) Myers, R. H.; Montgomery, D. C.; Anderson-Cook, C. M. Response Surface Methodology: Process and Product Optimization Using Designed Experiments, 4th ed.; John Wiley \& Sons: Hoboken, 2016, 1-856.

(31) Luong, M.; Domini, C. E.; Silbestri, G. F.; Chopa, A. B. J. Organomet. Chem. 2013, 723, 43.

(32) Pal, A.; Shah, S.; Devi, S. Mater. Chem. Phys. 2009, 114, 530.

(33) Huang, T.; Xu, X. H. N. J. Mater. Chem. 2010, $20,9867$.

(34) Nadagouda, M. N.; Speth, T. F.; Varma, R. S. Acc. Chem. Res. 2011, $44,469$.

(35) Montgomery, D. C. Design and Analysis of Experiments; John Wiley \& Sons: Hoboken, 2017, 9th ed. 614.

(36) Ahmadi, M.; Vahabzadeh, F.; Bonakdarpour, B.; Mofarrah, E.; Mehranian, M. J. Hazard. Mater. 2005, 123, 187.

(37) Orozco, F. D. A.; Sousa, A. C.; Domini, C. E.; Araujo, M. C. U.; Band, B. S. F. Ultrason. Sonochem. 2013, 20, 820.

(38) Krossing, I.; Raabe, I. Angew. Chem. Int. Ed. 2004, 43, 2066.

(39) (a) Yang, M.; Mallick, B.; Mudring, A. V. Cryst. Growth Des. 2014, 14, 1561. (b) Yang, M.; Mallick, B.; Mudring, A. Cryst. Growth Des. 2013, 13, 3068.

(40) Padma, D. K. Synth. React. Inorg. Met. Org. Chem. 1988, 18, 401.

(41) Agel, F.; Pitsch, F.; Krull, F. F.; Schulz, P.; Wessling, M.; Melin, T.; Wasserscheid, P. Phys. Chem. Chem. Phys. 2011, 13, 725. 